\title{
Нагреватели воздуха на базе позисторов
}

\author{
Т. Гужкова ${ }^{1}$, А. Раскин ${ }^{2}$
}

УДК 621.38 | ВАК 05.27 .01

\begin{abstract}
Основная продукция ОАО «ВЗРД «Монолит» (Беларусь, г. Витебск) многослойные керамические конденсаторы категорий качества "ВП", "OC", "ОСМ". Эти компоненты поставляются многим радиоэлектронным предприятиям России и используются в военной, авиационной, космической, атомной и другой специальной аппаратуре. В рамках конверсии в ОАО "ВЗРД "Монолит" создано импортозамещающее производство воздухонагревательных устройств.
\end{abstract}

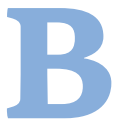
ыпускаемые в ОАО «ВЗРД "Монолит» нагревательные регистры (РН) предназначены для нагрева потока воздуха. Вывода (контакты) для подключения электропитания расположены на торцевой поверхности регистра (рис. 1).

Внутри регистра находятся нагревательные элементы - терморезисторы с положительным температурным коэффициентом сопротивления (другие названия - позисторы, РТС термисторы, РТС thermistors). Такой позистор

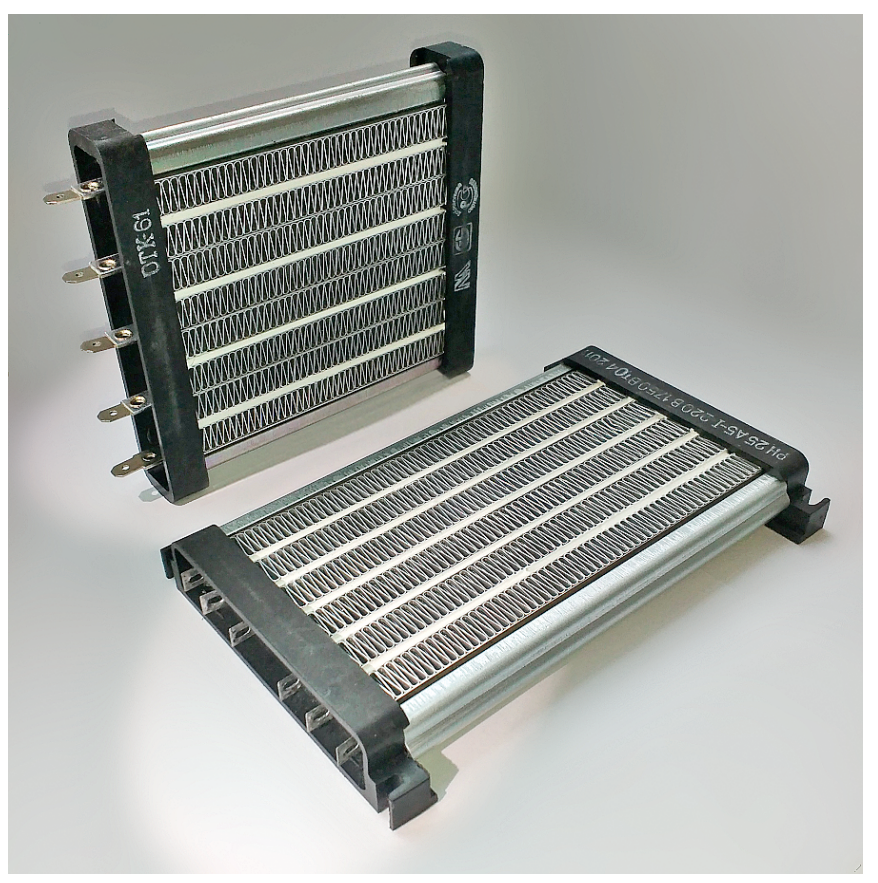

Рис. 1. Позисторные воздухонагревательные регистры серии РН (типы РН 25A5-I и РН 33A4-IV)

ОАО “ВЗРД “Монолит», главный технолог по изделиям электронной техники, начальник конструкторско-технологического отдела. ОАО «ВЗРД "Монолит», ведущий специалист по изделиям электронной техники, kto@monolit.by. представляет собой плоскую пластину из особой полупроводниковой керамики с металлизированными контактными поверхностями (рис. 2).

Позистор имеет специфическую нелинейную зависимость сопротивления от температуры (рис. 3). Если температура повышается и проходит точку переключения, сопротивление позистора многократно увеличивается, а потребляемая мощность во столько же раз уменьшается. Эта обратная связь не позволяет температуре позистора существенно превысить точку переключения.

Тепло, выделяемое позисторами, передается металлическому решетчатому радиатору. Через радиатор проходит поток воздуха, создаваемый вентилятором (в состав регистра он не входит).

ОАО "ВЗРД “Монолит» является единственным производителем позисторных воздухонагревательных регистров в странах СНГ. Но за пределами СНГ нагреватели аналогичной или схожей конструкции выпускают десятки фирм. Они заняли большую часть мирового рынка, потеснив традиционные воздухонагревательные элементы - открытые спирали и трубчатые электронагреватели (ТЭН).

Потребляемую мощность регистра и мощность нагрева воздуха можно регулировать двумя способами:

- ступенчатое регулирование - за счет включения и выключения отдельных секций регистра;

- плавное регулирование - за счет изменения производительности (скорости) воздушного потока (чем интенсивнее поток, тем больше мощность нагрева воздуха).

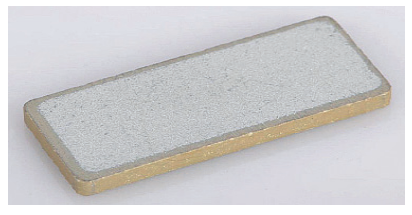

Рис. 2. Позистор для воздухонагревательной техники 


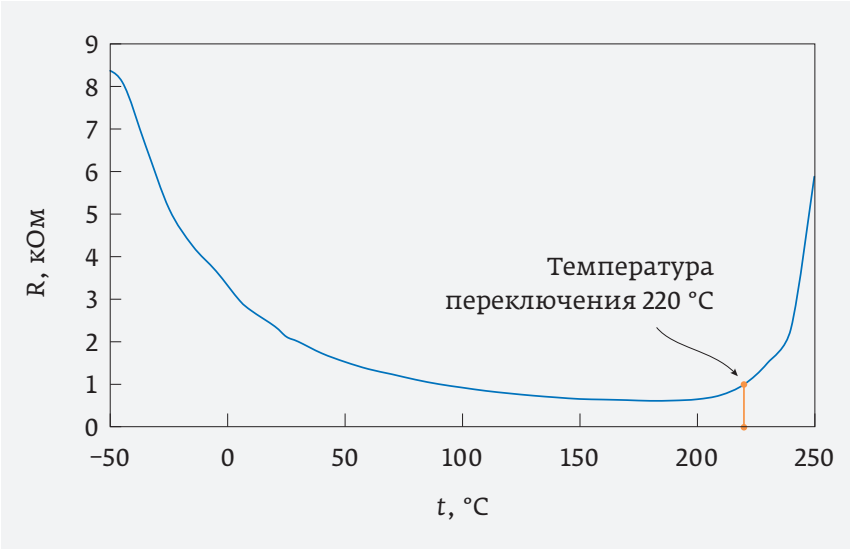

Рис. 3. Зависимость сопротивления от температуры для одного из типов позисторов

Основные достоинства и преимущества позисторных воздухонагревательных регистров:

- способность самостоятельно ограничивать температуру нагревателя за счет вышеуказанной уникальной зависимости R(t). Благодаря этому свойству максимальная температура поверхности регистра серии РН даже в аварийном режиме (при остановке вентилятора) не превышает $250^{\circ} \mathrm{C}$, что обеспечивает пожарную безопасность регистра. (В отличие от регистров, нагревательным спиралям и ТЭНам для автоматического ограничения температуры требуются дополнительные дорогостоящие устройства - датчики, регуляторы, термостаты и т.п.);

- высокая удельная мощность, приходящаяся на единицу площади поперечного сечения воздушного канала;

- надежность, способность выдерживать значительные скачки напряжения;

- низкая интенсивность инфракрасного излучения, что позволяет располагать рядом с регистрами детали из нетермостойких пластмасс и двигатели вентиляторов, не опасаясь их перегрева;

- экологическая чистота: при работе не сжигается кислород воздуха, не образуются угарный газ и другие вредные вещества, нет специфического запаха горения частиц пыли (что характерно для высокотемпературных ТЭНов);

- простота монтажа;

- удобство обслуживания и ремонта;

- длительный срок службы, который не зависит от количества включений / выключений и во много раз превышает срок службы ТЭнов.

К последнему пункту можно добавить данные компании "Лаборатория Климата" [1]. Она утверждает, что срок непрерывной работы позисторных регистров составляет не менее 20 тыс. часов без изменений основных характеристик (точка переключения и сопротивление). Если в конкретной климатической системе незначительный уход точки переключения от расчетного значения не играет большой роли, то ресурс работы регистра может быть увеличен до 30-40 тыс. часов. При этом количество включений и выключений никак не влияет на срок службы позистора. В ТЭнах же необратимые изменения (образование нагара на поверхности нихромовой спирали, а вследствие этого - неравномерный нагрев поверхности) могут возникнуть уже после 2-3 тыс. часов непрерывной работы, а регулирование выходной температуры воздуха посредством постоянного включения / отключения (термостаты, регуляторы) намного сокращает это время.

Основные области применения позисторных воздухонагревательных регистров:

- бытовые и промышленные тепловентиляторы, тепловые пушки;

- воздушные тепловые завесы;

- кондиционеры;

- электрокалориферы и канальные нагреватели в системах воздушного отопления и приточновытяжной вентиляции, в климатических системax;

- электрические обогреватели и отопители в транспорте;

- сушилки для рук;

- посудомоечные машины;

- системы сушки воздуха;

- технологические установки для сушки различных изделий;

- встроенные обогреватели внутреннего объема корпусов или шкафов с электронным оборудованием, системами автоматики, сигнализации и т. п., которые должны работать в неотапливаемых помещениях или контейнерах в условиях низких температур окружающей среды;

- прочее промышленное, транспортное, медицинское оборудование, в котором требуется нагрев воздуха.

ОАО "ВЗРД «Монолит» выпускает позисторные регистры серии РН по техническим условиям ТУ ВҮ300050407.021-2005 либо по согласованным техническим требованиям. В каталоге 2019 года представлено более 120 типов регистров. Один из типов показан на рис. 4

Основные технические характеристики регистров:

- общие для всех регистров:

- рабочее напряжение: 220 В / 50 Гц. Регистры могут включаться в трехфазную сеть по схеме "звезда»;

- рабочий диапазон температур: от -50 до $45^{\circ} \mathrm{C}$; 

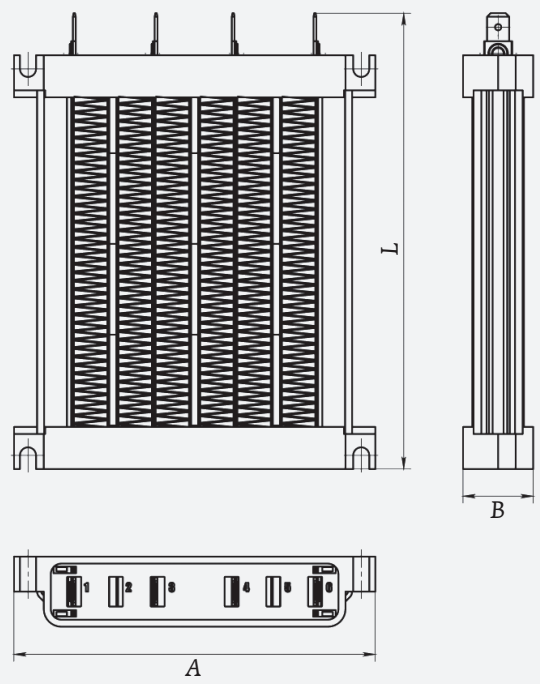

- характеристики, зависящие от типа регистра

- количество тепловых каналов (секций, рядов с позисторами): 1-6;

- номинальная потребляемая мощность: 80-2200 Вт (измеряется при скорости воздушного потока 5 м / с). Максимальная мощность достигается регистром PH 35A6-IV;

- габаритные размеры: $L=49-178$ мм, $A=58-116$ мм, B=20 мм (рис. 4);

- способ крепления в оборудовании: винтами или защелками;

- вывода (контакты) - паяемые или ножевые, направлены в одну сторону или в обе стороны.

Подробные сведения о регистрах серии РН содержатся в каталоге, размещенном на сайте [2]

Для мощныхвоздухонагревательныхустройств (промышленных тепловентиляторов, электрокалориферов, канальных нагревателей и т.п.) можно изготавливать тепловые панели (несколько регистров на одном шасси, рис. 5).

Межведомственный экспертный совет Департамента по энергоэффективности Государственного комитета по

\section{0 ИНТЕРНЕТ-МАГАЗИН CMП www.SMD.ru электронные компоненты для поверхностного монтажа}

\section{НОВОЕ В ПРОГРАММЕ ПОСТАВОК}

- Низкоомные резисторы типоразмеров 0402 и 0603

- Керамические конденсаторы большой емкости

Москва, Ленинградский пр., 80 к. 32; e-mail: sale@smd.ru Тел.: (499) 158-7396, (495) 940-6244, (499) 943-8780

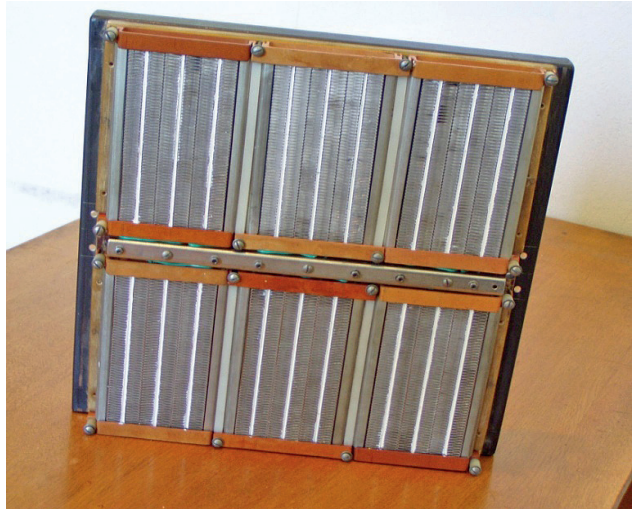

Рис. 5.

Панель, состоящая из шести регистров

стандартизации Республики Беларусь в 2009 году принял решение

- считать позисторные воздухонагревательные устройства энергоэффективным импортозамещающим оборудованием для технологических целей и целей нагрева;

- рекомендовать министерствам, ведомствам, организациям:

- внедрение позисторных воздухонагревательных устройств для технологических целей и целей нагрева на объектах народного хозяйства республики;

- замену используемыханалогичныхвоздухонагревательных устройств с традиционными нагревателями (ТЭН) на энергоэффективные позисторные воздухонагревательные устройства.

Воздухонагревательные регистры, выпускаемые ОАО "ВЗРД «Монолит», поставляются многим предприятиям России и Беларуси. Они нашли применение в бытовых и промышленных тепловентиляторах, малогабаритных приточных установках (для офисов и квартир), тепловыхпанелях для промышленных приточных установок, калориферахдля подвижного состава железных дорог, малогабаритных тепловентиляторах, встроенных в оборудование.

ОАО «ВЗРД «Монолит» предлагает сотрудничество всем разработчикам оборудования, которые решают задачу нагрева воздушного потока. Конструкторско-техническое бюро помогает потребителям подобрать регистры для конкретных задач и при необходимости разрабатывает регистры по спецзаказам.

\section{ОАО «ВЗРД «Монолит»}

Республика Беларусь, г. Витебск

Teл. : +375 (212) 364505, факс +375 (212) 364407,

e-mail:info@monolit.by

Конструкторско-техническое бюро:

men.: +375 (212) 364421, e-mail: kto@monolit.by

\section{ЛИТЕРАТУРА}

1. Нагреватели в системах приточной вентиляции на базе Р.Т.С. термисторов // Мир климата. 2005. № 33.

2. www.monolit.by 


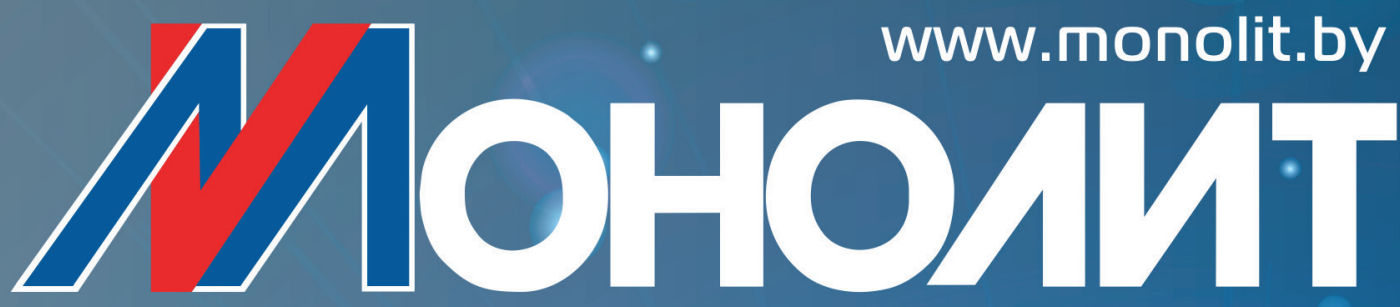

$*$

МНОГОСАОЙНЫЕ КЕРАMИЧЕСКИЕ КОНАЕНСАТОРЫ

\section{ИМПОРТОЗАМЕШАЮШАЯ} ПРОАУКЦИЯ

м^я высоконацёжной аппаратуры

ТЕРМОРЕЗИСТОРЫ

с положительным температурным коэффициентом сопротивления

\section{РЕГИСТРЫ} НАГРЕВАТЕАЬНЫЕ

210101, РЕСПУБАИКА БENAPУСЬ г. Витебск, ул. М. Горыкого, 145

ОтАел маркетинга: тел.: + 375 (212) 36-44-52 факс: + 375 (212) 36-44-53 e-mail: monolmarket@mail.ru

ОтАел процаж: тел: + 375 (212) 36-45-34 факс: + 375 (212) 36-44-65 e-mail: monosbet@mail.ru
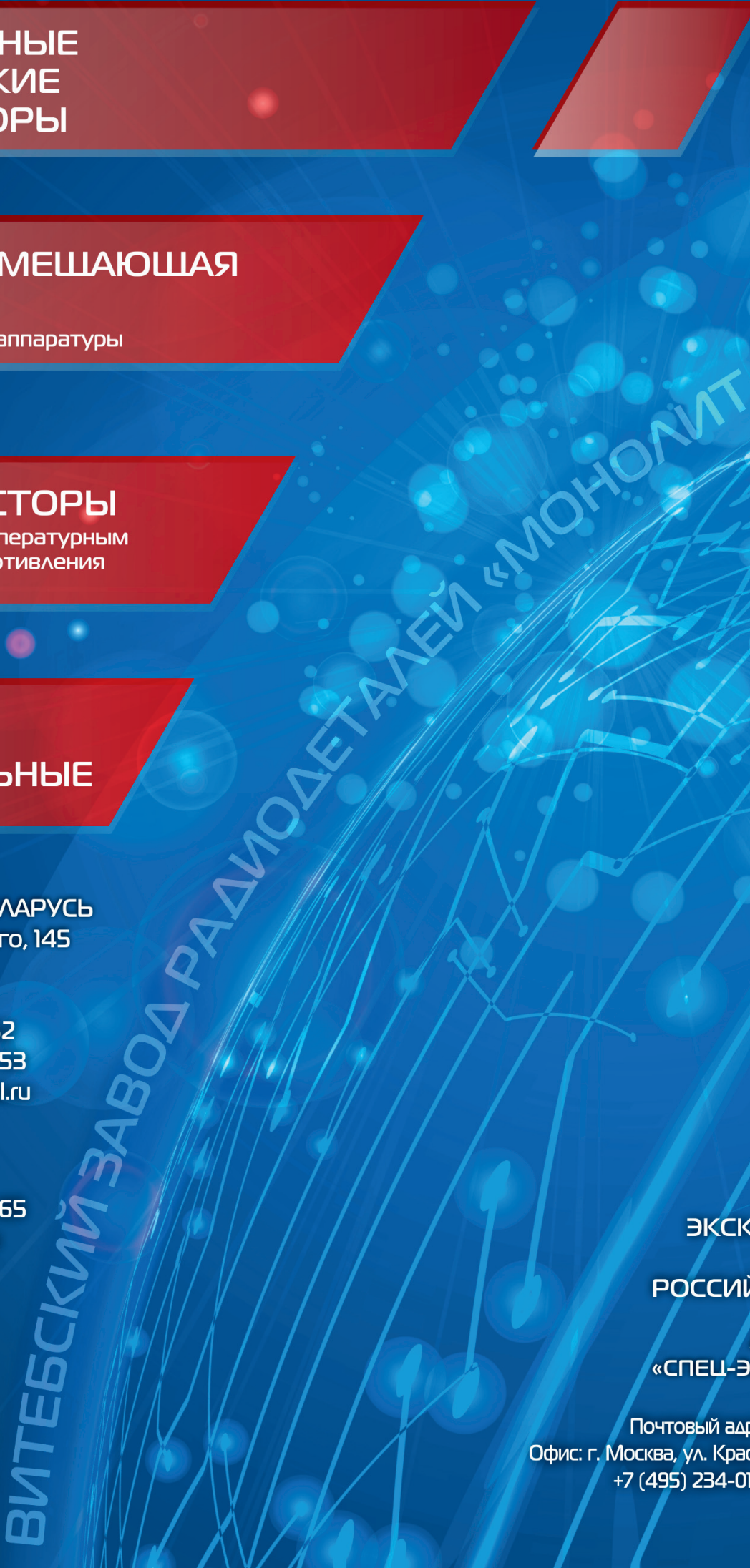